Revista de la red interuniversitaria de estudios sobre las literaturas rioplatenses contemporáneas en Francia

$10 \mid 2014$

El XIX en el XX

\title{
Cuatro versiones de Moreira
}

\section{Carlos Gamerro}

\section{OpenEdition}

Journals

\section{Edición electrónica}

URL: http://journals.openedition.org/lirico/1704

DOI: 10.4000/lirico.1704

ISSN: 2262-8339

Editor

Réseau interuniversitaire d'étude des littératures contemporaines du Río de la Plata

\section{Referencia electrónica}

Carlos Gamerro, « Cuatro versiones de Moreira », Cuadernos LIRICO [En línea], $10 \mid 2014$, Puesto en línea el 15 marzo 2014, consultado el 19 abril 2019. URL : http://journals.openedition.org/lirico/1704 ; DOI : $10.4000 /$ lirico. 1704

Este documento fue generado automáticamente el 19 abril 2019.

\section{(c) (i) (2)}

Cuadernos LIRICO está distribuido bajo una Licencia Creative Commons Atribución-NoComercialSinDerivar 4.0 Internacional. 


\title{
Cuatro versiones de Moreira
}

\author{
Carlos Gamerro
}

\section{NOTA DEL AUTOR}

Próxima publicación: Penguin Random House, 2015

1 "Edad: 46 a 48 años. Estatura : regular y algo grueso. Color : blanco, colorado, picado de viruelas. Pelo : castaño, barba afeitada, bigote solo, castaño. Nariz aguileña, boca grande, ojos verdosos grandes. Señas particulares : un balazo en la boca recibido hace doce días ; una herida en la mano inferida en la misma fecha."

2 Hasta aquí, la descripción del guardaespaldas y matón electoral Juan Moreira, muerto por la policía bonaerense el 30 de abril de 1874, tomada de un exhorto judicial librado pocos días antes. Ahora, la de su primera versión ficcional, la novela de folletín publicada por Eduardo Gutiérrez en La Patria Argentina entre noviembre de 1879 y enero de 1880, retrato que corresponde también, según declara el autor, al año de 1874 : "Su hermosa cabeza estaba adornada de una tupida cabellera negra, cuyos magníficos rizos caían divididos sobre sus hombros ; usaba la barba entera, barba magnífica y sedosa que descendía hasta el pecho, sombreando graciosamente una boca algo gruesa donde se hallaba eternamente dibujada una sonrisa de suprema amargura. Sus más hermosas facciones eran los ojos y la nariz: los primeros iluminaban su semblante atrayente, dándole una expresión inteligente y altiva ; la segunda, ligeramente aguileña, contribuía a aquella expresión de simpática bravura que dominaba en aquel semblante."

La historia de Moreira es una historia de transformaciones, de versiones que van de la crónica policial al folletín a la pantomima al teatro al cine y el cuento corto, casi todas las cuales, con la excepción de la crónica policial y el cuento corto, lo suponen, o lo presentan como, un mito popular - pero no se trata de un mito popular que estos textos recogen, sino de un mito popular que estos textos crean: Moreira es el primer héroe popular de nuestra cultura de masas; y como tal señala el momento en que la cultura popular se encuentra con ésta y empieza a ser absorbida por ella. No hay un culto de Juan Moreira, como sí lo hay del Gauchito Gil, muerto más o menos para los mismos años, y de tantos 
otros 'santos gauchos', ni su historia ha circulado de boca en boca, modificándose y enriqueciéndose - pero sí de texto en texto. Tampoco ha sido objeto de ninguna devoción peculiar, ni siquiera literaria, su primer autor, Eduardo Gutiérrez ; "Inútil pretender que perdura en el alma de su pueblo" apunta lacónicamente Borges en "Eduardo Gutiérrez, escritor realista" (Textos cautivos, 9 de abril de 1937).

Las entregas de Juan Moreira empiezan a salir el mismo año en que se publica La vuelta de Martín Fierro, y ciertas continuidades son evidentes : Moreira es, como Fierro, un gaucho manso y respetuoso de la autoridad, hasta que las persecuciones del teniente alcalde (el 'amigo Francisco') que codicia a su mujer, y la estafa del almacenero Sardetti, que se rehúsa a pagarle una deuda contraída de palabra, lo obligan a 'desgraciarse' matando a ambos, y de yapa a dos policías. En el inicio su historia sigue más de cerca la de Cruz que la de Fierro: como las suyas, sus desgracias comienzan porque el comandante militar codicia a su mujer, luego deberá otras muertes, será protegido por la autoridad y llegará a sargento de partida, renunciará, pasará un tiempo entre los indios...

Como en Martín Fierro, también aquí encontraremos la denuncia de las leyes, y del abuso de las autoridades de campaña, pero las de Gutiérrez suenan a hueco, como si estuviera repitiendo algo que leyó en otra parte; hasta su misma indignación suena impostada : "Es preciso convencerse "una vez para todas" de que el gaucho nocecilia2014-03-27T11:06:00 es un paria sobre la tierra que no tiene derechos de ninguna clase, ni aun el de poseer una mujer buena moza en contra de la voluntad del teniente alcalde. El gaucho es un hombre para quien la ley no quiere decir nada más que esta gran verdad práctica; el juez de paz de partido tiene derecho a remacharle una barra de grillos y mandarlo a un cuerpo de línea." Lo que la historia de Moreira ilustra, además, es la persecución de un individuo por el capricho de otro; el drama social de Martín Fierro condesciende en Juan Moreira a melodrama; la gauchesca deja de ser política y social y empieza a hacerse policial. Como señala Ezequiel Martínez Estrada en Muerte y transfiguración de Martín Fierro, Eduardo Gutiérrez sirve, "sin quererlo conscientemente, a la causa de los que preferían [...] al forajido sin la injusticia social, que podía suplantarse con la injusticia del funcionario, como solemos hacer en nuestro juicio de la vida política nacional. Eso es el Juan Moreira: una obra que reemplazó la injusticia social, el desorden gubernamental, con la injusticia personal del funcionario, la mala política con el mal político, la causa verdadera con uno de sus agentes ejecutivos."

6 Fierro es un gaucho como todos, Moreira pertenece a la categoría del individuo excepcional, como anuncia el primer párrafo de la novela : "Juan Moreira es uno de esos seres que pisan el teatro de la vida con el destino de la celebridad; es de aquellos hombres que [...] vienen a la vida poderosamente tallados en bronce." Una y otra vez Gutiérrez destaca los atributos que lo ponen por encima del común de los mortales: "su hercúleo brazo", "su hercúleo pecho", su "pujanza sobrehumana", "su pupila fosforescente" que lanza "intensos rayos de cólera cuyo contacto abrasador acobardaba a sus enemigos"; pelea solo contra partidas cada vez más numerosas y las derrota a todas; su daga legendaria "en nada se parece a la que usan la generalidad de nuestros paisanos" : mide ochenta y cuatro centímetros de largo, y "es digna de figurar en un museo al lado de la espada del Cid". Moreira es el gaucho matrero vuelto superhéroe ; su lujosa vestimenta, un traje de Superman : "Era un paisano hermoso, que vestía con un lujo deslumbrador. [... ] Su pequeño pie estaba calzado con una rica bota granadera, de cuero de lobo, que sujetaba al empeine con una lujosa espuela de plata con incrustaciones de oro. Llevaba bombacha de casimir negro, sujeta a la cintura por un tirador de charol, abotonado con 
monedas de oro y adornado con pequeñas monedas de plata [...] Detrás, asomando por ambos costados, aquel hombre traía una larga daga en vaina de plata, con una S de oro cincelado," (que sobre el final se corregirá a U) "que despertaba envidia en cuantos la veían."

$7 \mathrm{Su}$ origen gauchesco implica algunas diferencias fundamentales entre Moreira y los héroes de folletín que lo preceden y los superhéroes que lo sucederán: no es ni un bandolero - el bandolerismo no prende en la gauchesca ${ }^{2}$ - ni, propiamente hablando, un justiciero: no castiga injurias ni maldades inferidas a otros, y aunque pueda vengar las propias, tampoco es un vengador a lo Edmundo Dantés : su rodada "por la pendiente del crimen" comienza con la venganza ejecutada sobre el almacenero Sardetti y el 'amigo Francisco', pero no se trata de una venganza planeada ni demorada: le hacen una perrada, va y los mata de una. Su propósito, a partir de allí, será desafiar a la ley, 'pelear por lujo' para demostrar que es valiente, enfrentar a otros cuchilleros que lo desafían como luego harán los guapos de Borges. Como ellos, Moreira es un héroe de las orillas de Buenos Aires - nace en Flores, vive en La Matanza, muere en Lobos; es medio gaucho y medio matón de comité, viste "con un traje que no era de ciudad ni de campo, siendo mezcla de los dos" : Juan Moreira hace de puente entre la gauchesca y la futura literatura de orilleros : la de Carriego (el Carriego depurado por Borges) y la del mismo Borges.

En su poema "El tango" Borges escribió "una canción de gesta se ha perdido / en sórdidas noticias policiales". Gutiérrez intenta escribir las dos cosas a la vez, y su Moreira oscila más o menos sin control entre mito y caso policial, entre héroe popular y matón electoral, entre hombre de honor y fullero tramposo, entre inocente perseguido y fiero criminal, entre marido fiel y borracho putañero. Un vaivén parecido afecta las lealtades de su autor : acusa a las leyes de campaña y a 'la autoridá' pero cada vez que aparece uno de sus representantes lo trata de "apreciadísimo caballero", "persona conocida como recta y honorabilísima" etc. etc.; chupada de medias que alcanza su apoteosis con las del doctor Alsina, del cual Moreira fuera guardaespaldas en la vida real, el cual, en la novela, "le hablaba en lenguaje sencillo y noble, en ese único lenguaje que, dirigido al corazón del gaucho, hace de este hombre un niño dócil a quien se puede manejar hasta con la expresión de la mirada" en respuesta a lo cual "el paisano, lleno de inteligencia, comprende que aquel es un hombre superior que desciende hasta él y se le nivela como un igual".

El Moreira de Gutiérrez tiene bien en claro quiénes son sus superiores, y también sus inferiores. En el capítulo "El último asilo" Gutiérrez cumple con otro homenaje al Martín Fierro y obligado rito de pasaje del género : el cruce de la frontera. "Así llegó Juan Moreira para hacerse olvidar de la justicia, compartiendo con los indios esa vida nauseabunda del ocio y la borrachera." Si el de Fierro es un descenso a los infiernos del cual sale purgado de barbarie (sobre todo por su defensa de la cautiva, único acto altruista del 'paladín gaucho' en el poema) y dispuesto a tolerar las exigencias que la civilización trae consigo, la temporada de Moreira entre los indios uno de los momentos de envilecimiento en este continuo vaivén : "Moreira se hizo en los toldos un gran bebedor y un jugador malicioso, desplegando un talento especial para hacer trampas con la baraja". Su salida es un momento picaresco más digno de Picardía que de Fierro: juega con su anfitrión, el cacique Simón Coliqueo, le hace trampa y cuando éste protesta lo ciega de un hachazo entre las cejas y se da a la fuga.

En la línea de la gauchesca clásica, Gutiérrez continúa el exorcismo del rosismo y de la montonera : el Moreira histórico era hijo de un mazorquero que el mismo Rosas se había 
visto obligado a hacer fusilar para contener sus desmanes ; Gutiérrez menciona el caso al pasar, pero aclarando que su Moreira se crió "sin haber conocido a su padre" y nunca más se volverá a hablar del "tremendo Moreira que hizo fusilar Rosas" : los pecados del padre no caen sobre el hijo, y Moreira hijo nace libre de manchas. Fierro y Cruz conforman una minimontonera de dos para pelear a la partida, lo que los coloca no solo fuera de la ley sino de la sociedad: deben irse a vivir entre los indios. Esta osadía ya no volverá a repetirse: Moreira rechaza toda ayuda, aunque la partida cuente con veinticinco hombres : toda su gloria, todo su prestigio, toda su hombría se basan en que pelea siempre solo: "La temeridad de Moreira no reconocía límites. Sabía que un hombre guapo no sellaba sus hechos si no había peleado a la partida, los cual constituye la demostración más positiva de valor que puede hacer un gaucho, y la esperaba, para dejar antes de irse bien sentada su fama de guapo.

- Es preciso que usted se vaya - dijo a Julián - ; no quiero que digan que me hago acompañar porque tengo miedo, o porque no me considero suficiente."

11 Martínez Estrada ve en esto nada menos que la muerte del género : "El ramal de la poética gauchesca muere [...] en las novelas de Eduardo Gutiérrez y en el teatro de Podestá, Fontanella, Coronado. ¿Por qué este tipo de gran literatura sucumbe tan miserablemente en una caricatura grotesca ? La mitificación de Martín Fierro en héroe de cuchillo condujo a ese fin. [...] Querer hacer un héroe de Martín Fierro a costa de su destreza de peleador era dar directamente en su doble : Juan Moreira."

La novela de folletín Juan Moreira fue, como todo producto de la cultura de masas, una obra escrita para el pueblo pero no por el pueblo. Lo mismo, claro, podría decirse de Martín Fierro y de toda los gauchesca, aunque el público mayormente analfabeto que oía leer el Martín Fierro no era el mismo que leía Juan Moreira : éste era un público nuevo, tanto criollo como de origen inmigrante, la primera camada surgida de los procesos de alfabetización, que no tenía una relación previa con la literatura. Hernández y Gutiérrez escriben para el pueblo, pero mientras el primero supone un alto nivel de escucha y de apreciación estética y moral en el paisano, y se propone elevarlo aun más, Gutiérrez escribe para el bajo discernimiento que le supone a su público, y nivela su obra con éste.

La lectura, y más aun la relectura de Juan Moreira puede resultar una experiencia penosa. Su prosa es desmañada y floja, plagada de lugares comunes, de imprecisiones y vaguedades; Gutiérrez parece escribir con el codo izquierdo y sin ganas. Aun en las escenas de mayor dramatismo, como la de la pelea final de Moreira, es capaz de infligirnos párrafos exangües como éste, "Larsen había quedado completamente asombrado: la vista de Moreira, que avanzaba decidido aunque vacilante, lo había impuesto de tal modo, que no tuvo aliento para disparar su revólver y su brazo derecho cayó a lo largo del cuerpo, completamente debilitado por el terror", que alternan con frases briosas pero ineptas, como "aquella daga imponderable se movía en todas direcciones como una culebra de acero en contacto con una pila eléctrica". Juan Moreira es de esas novelas que indefectiblemente mejoran en el recuerdo; y Borges, para poder elogiarla sin culpa, recurre a este subterfugio. "Además, ciertas peleas de Gutiérrez son admirables. Recuerdo una, creo que la de Juan Moreira y Leguizamón. Las palabras de Gutiérrez se me han borrado ; queda la escena" ("Eduardo Gutiérrez, escritor realista").

14 Algo parecido sucede en el texto teatral de Juan J. Podestá, que sin dejar de ser un melodrama popular, presenta una acción vibrante y atrapadora, y diálogos conmovedores, y sobre todo creíbles. Pero la sorpresa del lector es mayúscula (la mía lo fue) cuando vuelve al texto de Gutiérrez y comprueba que las acciones son las mismas, y 
los diálogos palabra por palabra idénticos. Había una pequeña obra maestra escondida en el folletín de Gutiérrez, pero había que retirar toda la hojarasca que la disimulaba. Esa hojarasca era la narración. ¿A qué podrá deberse esta diferencia ? Podría pensarse que Gutiérrez fue uno de esos autores que tuvo la desgracia de no darse cuenta que cultivaba el género equivocado, que lo suyo era el teatro ${ }^{3}$. Otra respuesta posible es que Gutiérrez cree en la voz del gaucho, pero desconfía de la propia (así, al menos, parecen sugerirlo los comentarios con que desmerecía su obra ante los 'verdaderos' escritores). La tercera respuesta, a mi entender la más interesante, es la que propone Josefina Ludmer en $\mathrm{El}$ género gauchesco. Un tratado sobre la patria: hay gauchesca "cada vez que aparece una palabra escrita que se dice la voz del gaucho"; después de La vuelta de Martín Fierro, que cierra el género, "se abre otra cadena de usos : el uso del género para pasar a otro género literario : [...] a la novela, con las voces del gaucho y las palabras letradas delimitadas nítidamente, separadas, en Juan Moreira y Don Segundo Sombra." En Juan Moreira, a diferencia de lo que sucede en la gauchesca clásica, el gaucho ya no lleva la voz cantante, su voz está enmarcada, citada, por la voz culta del narrador: de ahí las comillas, las bastardillas, la vacilación entre tuteo y voseo. Así, también, el género es herido de muerte: narrador mata gauchesca (W. H. Hudson, en La tierra purpúrea, y Ricardo Güiraldes, en Don Segundo Sombra, encuentran la fórmula para conciliar novela y gauchesca, voz del gaucho y voz del narrador culto: ambas novelas son narradas en primera persona por hombres de ciudad que se van haciendo gauchos.)

El Moreira de Gutiérrez es un personaje a medio hacer, un gólem gaucho. En eso radica, paradójicamente, buena parte de su potencia. No hace falta aclarar, cuando se habla de Martín Fierro, que se trata de 'el Martín Fierro de Hernández' : todas sus encarnaciones posteriores no son sino versiones o repeticiones de aquel original. Moreiras, en cambio, hay tantos como autores capaces de crear una versión convincente del mismo. En esto se parece a Don Juan, que si tuvo un destacado comienzo en Don Juan y el convidado de piedra (1630) de Tirso de Molina, rebasa la obra que imperfectamente lo contiene, y pudo ser retomado por Molière, por Mozart y su libretista da Ponte, por José Zorilla, y en infinidad de novelas, cuentos y películas, y no hay una versión normativa (si bien puede argumentarse que en la de Mozart-da Ponte alcanza su punto más alto).

16 Más que la novela de Gutiérrez, fue la pieza de los hermanos Podestá la que grabó la imagen de Moreira en la memoria popular. El impacto, la potencia de contagio de este personaje larger than life que imperfectamente había vislumbrado Gutiérrez necesitó de la acción visible y los cuerpos presentes para imponerse como real, y tan real que pudo pasar de la escena al mundo circundante, según ilustran numerosas anécdotas que ilustran el efecto de la ilusión teatral en gentes que nunca habían asistido a un teatro. En la más famosa, un gaucho que asiste a la obra saca la daga y salta al picadero para defender a Moreira cuando la partida lo rodea. No sabemos si la historia es verdadera, pero nuestra credulidad la acepta sin reservas: versiones parecidas abundan en otras latitudes (hay una en la película The Piano (1993) de Jane Campion que involucra una versión de Barba azul y guerreros maoríes ; la más conocida de las letras españolas es, por supuesto, la aventura del retablo de maese Pedro en el Quijote). El salto barroco de este gaucho lo lleva del auditorio al escenario; otros hicieron el tránsito opuesto: según cuenta Borges en el prólogo de El gaucho (en Prólogos con un prólogo de prólogos) : "Un epigrama de Oscar Wilde nos advierte que la naturaleza imita al arte ; los Podestá pueden haber influido en la formación del guapo orillero que a fuerza de criollo acabó por identificarse con los protagonistas de sus ficciones. [...] En los archivos policiales de fines 
del siglo pasado o de principios de éste, se acusa a los perturbadores del orden "de haber querido hacerse el Moreira."” El tercer episodio concierne a la representación de Hormiga Negra, otro folletín de Gutiérrez llevado al teatro por los Podestá : deciden representarla en San Nicolás, de donde era el cuchillero ; éste, ya viejo y adecentado, se les aparece y los amenaza con estas palabras : "Andan diciendo - dijo - que uno de ustedes va a salir el domingo delante de toda la gente y va a decir que es Hormiga Negra. Les prevengo que no vana a engañar a nadie, porque Hormiga Negra soy yo y todos me conocen. [...] Si alguno salía diciendo que era Hormiga Negra, él, viejo y todo, lo iba a atropellar." (La anécdota, publicada en 1911 en Caras y Caretas, la recoge Borges en su prólogo al Fausto de Estanislao del Campo).

17 El público de esta pieza - de enorme importancia histórica como fundadora del teatro nacional, pero que pertenece, como el folletín que le dio origen, no a nuestra literatura viva sino al museo de nuestras letras - no siempre era tan ingenuo como estas anécdotas sugieren : así como la novela de Gutiérrez se sitúa en las orillas de la cultura popular (típicamente rural) y la cultura de masas (típicamente urbana), y su héroe en las orillas del campo y la ciudad, la obra Juan Moreira de los Podestá viaja también del campo a la ciudad, de la periferia al centro: de Arrecifes (1886) a Chivilcoy, luego al circo de la esquina de Europa y Piedras en los arrabales de Buenos Aires, luego Montevideo, de ahí al centro de Buenos Aires : al circo de Montevideo y Sarmiento y la definitiva consagración en el Politeama, donde noche a noche convocó a esa "juventud high-life" (los "Balcarce, Juancito Varela, Saturno Unzué, Mackinlay, Catelin, Arriola, Ferro, Martín Echeverría, Ocampo, Urquiza, Frías, Lynch, Acevedo") que menciona la crónica del periódico Sud América intercalada en las memorias de Podestá ${ }^{4}$.

Masivo también fue el público de la película Juan Moreira de Leonardo Favio: unos dos millones y medio de espectadores. En ésta, el director y su coguionista, su hermano Zuhair Jorge Jury, vuelven a la novela de Gutiérrez, y si bien mantienen la mayoría de los personajes y episodios, cambian la secuencia y las causalidades, armando una verdadera secuencia progresiva en la que un Moreira perplejo se va degradando y envileciendo, de paisano a pueblero, de esposo fiel a putañero, de gaucho trabajador a matón electoral. Las desgracias de su Moreira empiezan, como las del de Gutiérrez, con la muerte de Sardetti, pero el teniente alcalde, que lo puso en el cepo pero no tiene designios sobre su mujer, queda para más adelante. Moreira huye a las tolderías, pero allí no hay burla, ni trampas en el juego, sino contemplación dolida de la miseria ajena : "mas me vale que a mi tierra me vuelva a pelear lo mío / me rebela el ser testigo de tanta hambruna y pobreza." Los cambios más significativos comienzan con la muerte de Juan Córdoba. Allí, todo está invertido : en la novela era Moreira el que, lujosamente ataviado, llegaba a la pulpería, era saludado con respeto por todos, pagaba los tragos ; y era Córdoba el que, desde un rincón, borracho y rencoroso, se negaba a beber, mascullaba ofensas y luego lo desafiaba abiertamente, obligándolo a matarlo. El Córdoba de Favio no tiene otra culpa que venir de la capital y ser guapo electoral, pero eso basta para que Moreira, borracho, se dedique a provocarlo, y apenas éste se acerca a su mesa para ver qué le pasa lo tiende de una puñalada, sin desafiarlo siquiera : casi una muerte a traición, para el código gauchesco (gauchesco, no gaucho). Esta muerte gratuita e injustificada hace por el Moreira de Favio lo que la muerte del Moreno había hecho por Martín Fierro: lo corre de los lugares moralmente simétricos de víctima y de justiciero, lo vuelve extraño a sí mismo, lo convierte en un personaje complejo. Su salida de la pulpería ilustra de manera admirable la irrelevancia, para el gaucho, de esta última etapa de las guerras civiles, cuando tan 
poco le iba en la victoria de uno $u$ otro bando: “AAndrade, quién era? Digo, ¿a quién maté ?" le pregunta Moreira a su amigo, y cuando éste le contesta que era un guapo del Partido Nacionalista, Moreira contesta : "Y bueh. Que viva Alsina entonces." Esta muerte marca, aunque no pueda saberlo aún, el inicio de su carrera de matón electoral. Cuando, gracias a este precedente, el Cuerudo lo invite a unirse a las filas alsinistas, prometiéndole un indulto (a esta altura Moreira se ha vengado también del teniente alcalde) Moreira se hará matón electoral y cambiará su traje de gaucho por el traje cruzado del guapo. Según Sarmiento, bastaba con ponerle al gaucho un frac para que quedara automáticamente civilizado ; en la lógica de la película de Favio, lo queda es envilecido.

En 1973 los agrupamientos de gauchos tienen mejor prensa que en 1879, y hasta el final de la historia Moreira, Andrade y el Cuerudo conformarán otra minimontonera que se disolverá con la captura de Andrade y la traición del Cuerudo, que fue quien lo tentó a entrar en la política, así como Andrade lo induce a salirse : en la lógica cada vez más religiosa de la película conforman ambos la figura del ángel bueno y el ángel malo de las moralidades medievales.

En la novela, el doctor Marañón era atacado por cinco asesinos a sueldo, y Moreira, que había rechazado una oferta de dinero para sumarse a ellos, los ataca y desbanda, porque, como explica Gutiérrez, "el gaucho es así, toma cariño a una persona siguiendo un impulso del corazón". Menos querendón, el Moreira de Favio se cuenta entre los asesinos de Marañón, y es su compadre Julián Andrade el que se niega a tomar parte, haciendo vacilar a Moreira a último minuto - vacilación que por poco le cuesta la vida. Seriamente herido en esta misión se debate entre la vida y la muerte, y en su delirio juega un truco con la muerte, y gana - pero la muerte se lleva a su hijo. (Muchos desde entonces se han sentido muy inteligentes y se siguen sintiendo muy inteligentes denunciado esta escena como afano de la partida de ajedrez de El séptimo sello de Bergman. Chocolate por la noticia : el cine de Favio, sobre todo en la etapa que comienza con esta película, es una trituradora antropófaga-pop que deglute y digiere con igual fruición los productos nacionales y extranjeros, de la alta cultura y de la cultura de masas). Reprendido por su fracaso, Moreira se pasa al partido de Mitre, en espera del indulto que los alsinistas le habían prometido en vano, por lo cual un cantor gaucho lo acusa públicamente de camaleón y vendido. El fracaso de la revolución mitrista sella su suerte : la partida que va a buscarlo a lo del Dr. Marañón apresa al Cuerudo, que se convierte, como en la novela, en su Judas ; sorprende a Andrade en el prostíbulo de La Estrella, y acorrala a Moreira en su cuarto, donde su prostituta, lejos de cualquier lealtad folletinesca, no hace más que lloriquear "no quiero morir, no quiero morir" hasta que logra sacarla. Luego viene la única escena de la película en que el Moreira de Favio realiza una hazaña sobrehumana : atraviesa un estrecho corredor lleno de soldados, y los va haciendo a un lado uno a uno a disparos, golpes y cuchilladas : cuando acaba con el último la cámara se centra en su rostro y su avance ya no es el de un guerrero triunfante sino el de un mártir agonizante que evoca no solo la pasión de Cristo sino la del Che Guevara (ambos, la película de Jesucristo y la de Che Guevara, proyectos largamente abrazados y nunca concretados por Favio). Moreira sale al patio, llega a la tapia que parece no tener fuerzas para trepar, y allí es asesinado por la espalda por el sargento Chirino, quien les clava una bayoneta en la espalda. Todavía clavado contra la pared consigue darse vuelta ${ }^{5}$, dispararle y matarlo. Luego gira, con la daga entre los dientes y el poncho en la mano, la imagen se congela ${ }^{6} \mathrm{y}$ se desrealiza, volviéndose figura pintada, ícono. 
Ha sido costumbre considerar al Moreira de Favio como el Moreira peronista, y más específicamente, el Moreira del peronismo revolucionario, menos por la filiación política del director, que nunca se encolumnó en 'la Tendencia', que por la coyuntura y la fecha de estreno : el 24 de mayo de 1973, exactamente un día antes de que asumiera la presidencia Héctor J. Cámpora. Pero vuelta a ver cuarenta años después, su Juan Moreira se deja leer mejor como drama sacrificial-cristiano que como epopeya revolucionaria : una película que se siente más cómoda en compañía de La pasión de Juana de Arco (1928) de Carl Theodor Dreyer, Toro salvaje (1980) de Martin Scorsese (que Favio reescribirá como drama sacrificial-peronista en Gatica, el Mono), Contra viento y marea (1996) de Lars von Trier y hasta La pasión del Cristo (2004) de Mel Gibson, que encolumnada en lo que se entendía en su época por cine político : La batalla de Argelia (1965) de Gillo Pontecorvo, La hora de los hornos (1968) de Octavio Getino y Fernando Solanas, Operación masacre (1973) de Jorge Cedrón y aun de Los hijos de Fierro (1975) del mismo Solanas (difícil imaginar dos películas que intentan recuperar la rebeldía gaucha desde el peronismo, y que sean más distintas). Quizás sea un efecto de la lente distorsionadora de nuestra época, en la cual la religión ha vuelto por sus fueros, para librar sus guerras sin máscaras, pero a uno (al menos a mí) lo asalta por momentos la sospecha de que es al revés : que Juan Moreira de Favio fue siempre un drama sacrificial religioso, y que solo la enorme presión ideológica de la época, la figuración pública de su autor y la ocasión de su estreno llevaron a verla como película predominantemente política. En esto, también, se convirtió en cifra, y quizás profecía, de su generación, que quiso escribir una epopeya revolucionaria y terminó actuando sin quererlo, como el Baltasar Espinosa de Borges, una Pasión cristiana. A parecida tensión se ve sometida la historia del Che Guevara: con cada día que pasa la epopeya cubana va siendo opacada por la Pasión boliviana.

23 El Moreira de Favio es, antes que un mártir de la causa, o un héroe revolucionario, un hombre confundido, que comenzó como víctima del sistema pero que luego se fue envileciendo, y se siente abrumado, según sus propias palabras, por "esta vergüenza mía de verme sucio, sucio y tan culpable de algo que no comprendo, que me rodea desde hace tanto tiempo" - lo que lo coloca en la línea de otros personajes de origen popular en el cine del director, que 'se pierden' sin saber muy bien cómo ni por qué, como el Aniceto del Romance del Aniceto y la Francisca (1966) y el Gatica de Gatica, el Mono (1993) y luego, si pueden, buscan a tientas el camino de su redención.

Este Moreira tiene, sin duda, mucho de guapo : se descubre a sí mismo en un entrevero, como el Cruz de Borges, muere en su ley, peleando con la partida innumerable, demostrando su coraje (no nos dejemos distraer por nimiedades ideológicas : el peronista Favio, hombre y artista generoso como pocos, tenía al gorila Borges como una de sus lecturas de cabecera) - pero aquí terminan los parecidos. La continuidad entre los guapos seculares de Gutiérrez y Borges es tan notoria como llamativa es la ruptura con el mártir cristiano de Favio, más cercano al modelo del héroe pecador imaginado por la literatura medieval cristiana y más tarde recreado por Dostoievski. Este Moreira no muere defendiendo a los desposeídos, ni se redime de su vergüenza, como el Lord Jim de Conrad, dando la vida por una causa justa : cuando lo encuentra la partida sigue siendo un matón que se ha pasado al mitrismo casi porque sí, que ha dejado a su mujer por una puta: su justificación es cristiana en el más puro sentido del término: purificación por el sufrimiento, sacrificio por el sacrificio mismo, redención por la sangre. Carga con su cruz, es atravesado por una bayoneta, muere crucificado. 
25 Favio le devuelve al gaucho lo que la gauchesca le había quitado : su religiosidad, tanto la popular, que el director siempre ha defendido y asumido como propia en sus declaraciones, como la estrictamente cristiana; religiosidad que alcanza su mayor densidad justamente en las dos películas, Juan Moreira y Nazareno Cruz y el lobo (1975), de esta época donde la política parecía capaz de absorberlo todo. El arte de Favio (más que Favio mismo) entrevió en la figura de Moreira el futuro y la precaria justificación de una generación que marchaba a la muerte, premonición que él sería uno de los primeros en ver cumplida, a menos de un mes de su estreno, el 20 de junio de 1973, día en que tuvo que amenazar con suicidarse para evitar que los matones de la derecha peronista siguieran torturando a militantes de izquierda durante la llamada Masacre de Ezeiza.

26 El último acto de esta secuencia de metamorfosis era en realidad el penúltimo. Durante años creí que Borges escribió "La noche de los dones" como respuesta a la película de Favio $^{7}$, debido a que forma parte de El libro de arena, que es de 1975 ; pero la triste verdad es que ya había sido publicado en La Prensa en diciembre de 1971. Una vez más, el orden cronológico se da de patadas con el lógico : el cuento de Borges funciona perfectamente como glosa maliciosa e irónica de la epopeya de Favio : no tiene sentido en cambio ver en ésta una respuesta a un cuento menor de Borges. Éste, de todos modos, nunca habría ido a ver la película de Favio, no por su ceguera, ya que seguía yendo al cine, pero nunca a ver su peor pesadilla: una versión peronista de Juan Moreira. Más que clarividencia, tendríamos que hablar aquí de fatalismo resignado: viendo como inexorable el retorno del peronismo al poder, se habrá dicho "estos guarangos son capaces de cualquier cosa, hasta de hacer una película épica sobre Moreira”. Anticipó, no tanto el drama sacrificial que Favio realizó, sino la epopeya revisionista que todos creyeron que había hecho.

27 En el cuento de Borges, un grupo reunido en la antigua Confitería del Águila, entre los cuales se encuentran un Borges joven o niño y su padre, oye de labios de "un señor de edad" el relato de la muerte de Moreira, de la que éste fuera testigo ocular. A los trece años, de visita en Lobos, fue llevado por uno de los peones al prostíbulo de La Estrella. Allí, mientras jugaba con el perrito del burdel "para despistar o para que vieran que yo era un chico" escuchó de labios de una de las pupilas, conocida como la Cautiva, el relato del malón que se la había llevado, y que ella recitaba, más que contaba, siempre con las mismas palabras, "como quien dice una oración, de memoria". De la gritería evocada en la mente de su joven oyente pasamos a una gritería real : llegan Moreira y su gente, ya no gauchos sino "orilleros borrachos".

28 Aquí, Borges lleva a cabo una de esas piruetas en las que descollaba : vuelve al Moreira de la crónica policial, desmitificando al gaucho de la ficción, y al mismo tiempo reconoce la preeminencia de la ficción sobre la realidad, aun para aquellos que fueron parte de esa realidad: "Pasado el tiempo, ya no sé si me acuerdo del hombre de esa noche o del que vería tantas veces en el picadero. Pienso en la melena y la barba negra de Podestá, pero también en una cara rubiona, picada de viruela." A renglón seguido viene el momento más insidioso de su relato : "El cuzquito salió corriendo a hacerle fiestas. De un talerazo, Moreira lo dejó tendido en el suelo. Cayó de lomo y se murió moviendo las patas." Cheapest trick in the business : si quieren que un personaje le caiga antipático a los lectores, nada mejor que hacerlo matar un animalito simpático e indefenso. Se lo creería un recurso indigno de Borges, pero el viejo era más taimado e insidioso : este episodio es una revisión irónica de la novela de Gutiérrez, en la cual Moreira siempre va acompañado de su fiel cuzquito Cacique, que varias veces lo salva de la muerte, alertándolo del peligro con sus agudos ladridos. Cheapest trick in the business : si quieren que un personaje le caiga 
simpático a los lectores, nada mejor que mostrarlo mimando a un tierno animalito. Huyendo del peligro, el muchacho se refugia en uno de los cuartos, donde lo encuentra la Cautiva, que tras decirle "yo estoy aquí para servir, pero a gente de paz" lo inicia sexualmente. Escuchando luego la balacera, lo hace salir por una escalera que da a la calle, donde se encuentra con el sargento Chirino que espera a Moreira, y lo ejecuta en una escena purgada de cualquier resto épico : "Por la tapia un hombre se descolgaba. De un brinco, el sargento le clavó el acero en la carne. El hombre se fue al suelo, donde quedó tendido de espaldas, gimiendo y desangrándose. Yo me acordé del perro. El sargento, para acabarlo de una buena vez, le volvió a hundir la bayoneta. [...] Andrés Chirino tuvo que forcejear para arrancar el arma. Todos querían estrecharle la mano." (En las distintas versiones, la suerte de Chirino varía en relación inversamente proporcional a la heroicidad de Moreira : el de las crónicas pierde un ojo y cuatro dedos de un hachazo ; el de Gutiérrez recibe un balazo que tras rozarle el ojo y la pupila izquierda se incrusta en su pómulo ; el de Favio pierde la vida, el de Borges resulta indemne).

En sus párrafos iniciales, el cuento de Borges se anunciaba como reflexión sobre el problema del conocimiento - específicamente, sobre la tesis platónica de que "aprender es recordar" a la cual el señor de edad contribuye la historia de esa "noche de los dones" en que le fue dado conocer el amor y mirar la muerte; sobre el final recupera el proceso mediante la experiencia de uno se convierte en historia de todos: "los años pasan y son tantas las veces que he contado la historia que ya no sé si la recuerdo de veras o si sólo recuerdo las palabras con que la cuento. Tal vez lo mismo le pasó a la Cautiva con su malón. Ahora lo mismo da que fuera yo o que fuera otro el que vio matar a Moreira."

Pero es también, y quizás preponderantemente, un cuento político de la época - con piel de metafísico - y forma parte sin duda de esa revisión de la propia obra que Borges había emprendido, al calor de la violencia política de los 70. Hacia fines de 1969 publica "Historia de Rosendo Juárez" donde explica la inexplicable cobardía del guapo de "Hombre de la esquina rosada" : Juárez se harta de la violencia "porque sí", se niega a pelear y demuestra otra clase de coraje: el coraje de ser un hombre de paz, y de no importarle lo que puedan decir de él (tema que obsesiona a los guapos de Borges, y también a Moreira). Y de 1974 es esta autodefinición del "Epílogo" de sus Obras completas, en el que - temporariamente - abjura de su mitología de cuchilleros: "Pensaba que el valor es una de las pocas virtudes de las que son capaces los hombres, pero su culto lo llevó, como a tantos otros, a la veneración atolondrada de los hombres del hampa. [...] Su secreto y acaso inconsciente afán fue tramar una mitología de una Buenos Aires, que jamás existió. Así, a lo largo de los años, contribuyó sin saberlo y sin sospecharlo a esa exaltación de la barbarie que culminó en el culto del gaucho, de Artigas y de Rosas." Entre ambos, llevó a cabo esta desmitificación anticipada del imaginado (por él y por todos nosotros) Moreira peronista-revolucionario de Leonardo Favio.

\section{NOTAS}

1. Todas las citas de Ezequiel Martínez Estrada en este trabajo se refieren a este libro. 
2. En esto influye, sin duda, el hecho de que la gauchesca sea un género escrito por estancieros, y si no por ellos directamente, por miembros de su misma clase. Los males que se proponen remediar son políticos, más que socioeconómicos : el gaucho de la gauchesca trabaja en las estancias en armonía con el patrón hasta que las levas se lo llevan a la frontera, sea por azar o por causas políticas (Fierro, Picardía), sea porque 'la autoridá' codicia sus posesiones económicas o sexuales (Cruz, Moreira) : recién entonces se vuelve pobre y perseguido.

3. "Si Gutiérrez hubiera tenido la visión de que Moreira iba a ser la base del teatro nacional, se habría preocupado más de la obra, y, seguramente, habría escrito algo de más valor para la escena, y tan evidente es esto, que Gutiérrez nunca presenció su Moreira hablado" comenta Podestá en sus memorias.

4. Véase Viñas, David. La crisis de la ciudad liberal, cap. V: "El nuevo público. Moreirismo y antimoreirismo".

5. En la novela, le escupe una frase que resume el tan argentino desprecio por la ley y sus representantes (véase por ejemplo J. L. Borges, "Nuestro pobre individualismo”) : ¡No podés negar que sos justicia !” y que es elogiada por el guionista Z. J. Jury : "Las frases de Moreira son de una síntesis dramática tan increíble que parecen literarias, pero, en cambio, son reales. Cuando lo clavan por la espalda, gira y le dice al milico : jJusticia tenías que ser !" Revista Panorama, 18 de enero de 1973 (citado por Alberto Farina en Leonardo Favio). La frase no ocurre en la película.

6. Este congelamiento del héroe rebelde en el momento inmediatamente anterior a su ineludible muerte a manos de una apabullante mayoría de fuerzas del orden se da también en Butch Cassidy and the Sundance Kid (1969) de George Roy Hill y Thelma \& Louise (1991) de Ridley Scott.

7. No soy el único. "Al respecto, Jorge Luis Borges hará una reescritura de este mito en su cuento "La noche de los dones", perteneciente a El libro de arena, que contiene una crítica implícita al film de Favio: Borges se opone a la imagen de un Moreira revolucionario, vinculado al peronismo." Leemos en Leonardo Favio de Alberto Farina. 